\title{
Novel Electronically Tunable Biquadratic Mixed- Mode Universal Filter Capable of Operating in MISO and SIMO Configurations
}

Musa Ibharim Ali Albrni ${ }^{1}$, Faseehuddin Mohammad ${ }^{2}$, Norbert Herencsar $^{3}$, Jahariah Sampe ${ }^{1}$, Sawal Hamid Md Ali ${ }^{4}$

${ }^{1}$ Institute of Microengineering and Nanoelectronics (IMEN), University Kebangsaan Malaysia (UKM), Level 4 MINES Lab UKM Bangi, Selangor, Malaysia ${ }^{2}$ Faculty of Engineering, Symbiosis Institute of Technology (SIT), Symbiosis International University (SIU), Lavale, Mulshi, Pune, Maharashtra, India.

${ }^{3}$ Department of Telecommunications, Faculty of Electrical Engineering and Communication, Brno University of Technology, Brno, Czech Republic

${ }^{4}$ Department of Electrical, Electronic and Systems Engineering, Universiti Kebangsaan Malaysia (UKM), Faculty of Engineering \& Built Environment, UKM, Bangi, Selangor, Malaysia

\begin{abstract}
In this paper, a novel electronically tunable biquadratic universal mixed-mode filter is presented. The filter is based on extra $X$ current conveyor transconductance amplifier (EXCCTA), recently introduced by authors. The proposed filter employs two EXCCTAs, two capacitors, a switch, and four resistors. The filter can work in both multi-input-single-output (MISO) and single-input-multi-output (SIMO) configurations without change in its structure. The filter provides all five responses in voltage-mode (VM), current-mode (CM), transimpedance-mode (TIM), and transadmittance-mode (TAM). The attractive features of the filter include (i) ability to operate in both MISO and SIMO configurations in all four modes, (ii) no requirement of capacitive matching, (iii) tunability of quality factor (Q) independent of natural frequency $\left(\omega_{0}\right)$ in MISO \& SIMO configurations and (iv) no requirement for double/negative input signals (voltage/current) in MISO configuration. The non-ideal gain and sensitivity analysis is also carried out to study the effects of process variations and passive components spread on filter performance. The filter is designed in Cadence Virtuoso using Silterra Malaysia $0.18 \mu \mathrm{m}$ PDK. The complete layout of the EXCCTA is designed and the parasitic extraction is done. The filter is tested at a supply voltage of $\pm 1.25 \mathrm{~V}$ and the obtained results validate the theoretical findings.
\end{abstract}

Keywords: analog signal processing, voltage-mode, current-mode, transimpedance-mode, transadmittance-mode, extra X current conveyor transconductance amplifier, EXCCTA, universal filter

\section{Nov elektronsko nastavljiv bikvadratičen univerzalen filter $v$ mešanem načinu delovanja sposoben delovanja $v$ MISO in SIMO konfiguraciji}

\footnotetext{
Izvleček: Članek predstavlja nov elektronsko nastavljiv bikvadratičen filter v mešanem načinu delovanja. Filter sloni na dodatnem $X$ tokovnem transkonduktančnem ojačevalniku (EXCCTA). Filter je sestavljen iz dveh EXCCTA-jev, dveh kondenzatorjev, stikala in štirih tranzistorjev. Filter lahko deluje v eno-vhodni multi izhodni (MISO) ali multi-vhodno eno-izhodni (SIMO) konfiguraciji brez spremembe v strukturi. Ponuja vseh pet odzivov v napetostnem (VM), tokovnem (CM), transimpedančnem (TIM) in transadmitančnem načinu (TAM). Prednostne lastnosti filtra so (i) delovanje v MISO ali SIMO načini, (ii) ni potrebe po kapacitivnem ujemanju, (iii) nastavljivost faktorja kvalitete (Q) brez odvisnosti od osnovne frekvence v MISO in SIMO načinu in (iv) brez potrebe po dvojnem negativnem vhodu signal v MISO načinu. Opravljena je tudi analiza občutljivosti in ojačenja filtra zaradi variacij procesa in toleranc pasivnih komponent.

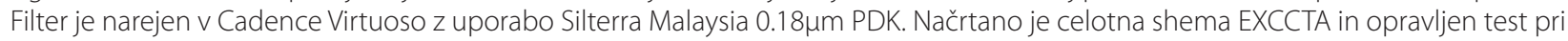
napajalni napetosti $\pm 1.25 \mathrm{~V}$.
}

Ključne besede: analogno procesiranje signalov, EXCCTA, univerzalen filter, transkonduktančni tokovni ojačevalnik 


\section{Introduction}

The design and development of frequency filters is an important field of communication engineering and research. The filters are an integral part of almost every electronic system [1-3]. The universal filter structure is the most versatile and sought-after filter configuration as it provides all five generic filter responses namely, lowpass (LP), high-pass (HP), band-pass (BP), band-reject (BR), and all-pass (AP) from same configuration. It serves as a stand-alone solution for all filtering requirements. They are employed in data acquisition systems as analog front-end, in communication systems, biomedical signal processing, instrumentation, and oscillator design, etc. [3-15]. Owing to their wide bandwidth, high slew-rate, simple circuit, good linearity, and better performance under low-voltage low-power (LVLP) environment currentmode (CM) active building blocks (ABBs) are preferred for designing analog filters $[2,5,6]$. The most popular CM $\mathrm{ABBs}$ are the second-generation current conveyor (CCII) [1-6], current feedback operational amplifier (CFOA)
[16], fully differential current conveyor (FDCCII) [18], differential voltage current conveyor (DVCC) [20], current controlled current conveyor transconductance amplifier (CCCCTA) [21], differential difference current conveyor (DDCC) [23], etc. In present day complex signal processing systems the need for interaction between currentmode and voltage-mode (VM) circuits arises often. This requirement can be met by employing transadmittancemode (TAM) and transimpedance-mode (TIM) circuits to facilitate distortion free interfacing between $C M$ and VM units [7-11, 23]. Although several TAM and TIM filter structures have been proposed, but a single topology providing the CM, VM, TAM, and TIM responses will be an added advantage in terms of area and power requirements. Numerous mixed-mode universal filters can be found in the open literature [7-34] that were designed to cater to the above-mentioned requirements. The filter structures can be classified in three basic groups such as single-input-multi-output (SIMO), multi-input-multioutput (MIMO), and multi-input-single-output (MISO). The comparison between the filter structures can be done based on following important criteria:

Table 1: Comparative study of the state-of-the-art mixed-mode designs with the proposed filter

\begin{tabular}{|c|c|c|c|c|c|c|c|c|c|c|c|c|c|c|c|}
\hline $\begin{array}{l}\text { Refer- } \\
\text { ences/ } \\
\text { Year }\end{array}$ & $\begin{array}{l}\text { Mode of } \\
\text { Operation }\end{array}$ & (i) & (ii) & (iii) & (iv) & (v) & (vi) & (vii) & (viii) & (ix) & $(x)$ & (xi) & (xii) & (xiii) & (xiv) \\
\hline [16]/2005 & SIMO & 3-CFOA & $9 \mathrm{C}+2 \mathrm{R}$ & Yes & No & Yes & No & Yes & No & Yes & N.A. & N.A. & N.A. & $112.5 \mathrm{KHz}$ & No \\
\hline$[17] / 2006$ & SIMO & 2-FTFN & $2 C+3 R$ & Yes & Yes & No & No & Yes & No & No & N.A. & N.A. & N.A. & $31.8 \mathrm{KHz}$ & No \\
\hline$[18] / 2008$ & SIMO & 1-FDCCII & $2 C+3 R$ & Yes & Yes & Yes & Yes & No & Yes & No & N.A. & N.A. & N.A. & $3.78 \mathrm{MHz}$ & No \\
\hline$[19] / 2008$ & SIMO & 5-MOCCCII & $2 C$ & Yes & Yes & Yes & Yes & No & Yes & No & N.A. & N.A. & N.A. & $638.4 \mathrm{KHz}$ & Yes \\
\hline [20]/2009 & SIMO & 3-DVCC & $2 C+3 R$ & Yes & Yes & Yes & Yes & Yes & Yes & No & N.A. & N.A. & N.A. & $16 \mathrm{MHz}$ & No \\
\hline$[21] / 2010$ & SIMO & 2 -CCCCTA & $2 C$ & Yes & Yes & Yes & Yes & No & No & No & N.A. & N.A. & N.A. & $1.134 \mathrm{MHz}$ & Yes \\
\hline$[22] / 2010$ & SIMO & 2-CCCCTA & $2 C$ & Yes & Yes & Yes & No & Yes & No & No & N.A. & N.A. & N.A. & $1.63 \mathrm{MHz}$ & Yes \\
\hline$[23] / 2011$ & SIMO & 3-DDCC & $2 C+4 R$ & Yes & Yes & Yes & Yes & No & Yes & Yes & N.A. & N.A. & N.A. & $3.97 \mathrm{MHz}$ & No \\
\hline$[24] / 2017$ & SIMO & 3-ССССТА & $2 C$ & Yes & Yes & Yes & Yes & Yes & Yes & Yes & N.A. & N.A. & N.A. & $3.183 \mathrm{MHz}$ & Yes \\
\hline$[25] / 2017$ & SIMO & 3-VDTA & $2 C$ & Yes & N.A. & Yes & Yes & N.A. & Yes & No & N.A. & N.A. & N.A. & $3.04 \mathrm{MHz}$ & Yes \\
\hline$[26] / 2017$ & SIMO & 6-OTA & $2 C$ & Yes & Yes & Yes & Yes & No & No & Yes & N.A. & N.A. & N.A. & $1.5 \mathrm{MHz}$ & Yes \\
\hline$[27] / 2017$ & SIMO & $\begin{array}{l}\text { 1-DVCC+ } \\
\text { 1-MOCCII }\end{array}$ & $2 C+3 R$ & Yes & No & Yes & Yes & No & Yes & No & N.A. & N.A. & N.A. & $1.59 \mathrm{MHz}$ & No \\
\hline$[36] / 2016$ & SIMO & 2-FDCCII & $2 C+5 R$ & Yes & Yes & Yes & Yes & No & No & Yes & N.A. & N.A. & N.A. & $1.59 \mathrm{MHz}$ & No \\
\hline [37]/2018 & SIMO & 2-FDCCII & $2 C+4 R$ & Yes & Yes & Yes & Yes & No & No & Yes & N.A. & N.A. & N.A. & $1.59 \mathrm{MHz}$ & No \\
\hline$[28] / 2004$ & MISO & 7-CCII & $2 \mathrm{C}+8 \mathrm{R}$ & Yes & Yes & N.A. & N.A. & N.A. & No & Yes & No & Yes & Yes & - & No \\
\hline [29]/2006 & MISO & $3-\mathrm{CCll}$ & $\begin{array}{l}\text { 3C+4R+ } \\
\text { 2-switch }\end{array}$ & No & No & N.A. & N.A. & N.A. & No & Yes & No & Yes & Yes & - & No \\
\hline [30]/2009 & MISO & 4-OTA & $2 C$ & Yes & Yes & N.A. & N.A. & N.A. & No & Yes & No & Yes & No & $1.59 \mathrm{MHz}$ & Yes \\
\hline$[31] / 2010$ & MISO & 2-MOCCCII & $2 C+2 R$ & Yes & Yes & N.A. & N.A. & N.A. & Yes & Yes & No & Yes & Yes & $1.27 \mathrm{MHz}$ & Yes \\
\hline$[32] / 2013$ & MISO & 4-MOCCCII & $2 \mathrm{C}$ & Yes & Yes & N.A. & N.A. & N.A. & No & Yes & Yes & Yes & No & 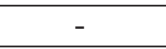 & Yes \\
\hline [33]/2016 & $\begin{array}{l}\text { SIMO/ } \\
\text { MISO }\end{array}$ & $\begin{array}{c}\text { 1-FDCCII+ } \\
\text { 1-DDCC }\end{array}$ & $2 C+6 R$ & Yes & Yes & Yes & Yes & Yes & Yes & Yes & No & Yes & No & $1.59 \mathrm{MHz}$ & No \\
\hline$[34] / 2018$ & MISO & 5-DVCC & $2 C+5 R$ & Yes & Yes & N.A. & N.A. & N.A. & Yes & No & No & Yes & Yes & $1 \mathrm{MHz}$ & No \\
\hline Proposed & $\begin{array}{l}\text { MISO/ } \\
\text { SIMO }\end{array}$ & 2-EXCCTA & $\begin{array}{c}\mathrm{C}+4 \mathrm{R}+ \\
\text { switch }\end{array}$ & Yes & Yes & Yes & Yes & Yes & Yes & Yes & Yes & Yes & Yes & $8 \mathrm{MHz}$ & Yes \\
\hline
\end{tabular}

*N.A. (not applicable) [points (v)-(vii) are not applicable in case of MISO filters, points (x)-(xii) are not applicable in case of SIMO filters, point (iv) is not applicable in case of resistor less filters] 
(i) number of ABBs employed,

(ii) number of passive components needed,

(iii) no need for capacitive matching,

(iv) no requirement for resistive matching except for AP response,

(v) use of grounded capacitors in SIMO configuration,

(vi) availability of explicit current output from high impedance node in SIMO configuration,

(vii) low input impedance for CM and TIM in SIMO configuration,

(viii) provision to control quality factor independent of the natural frequency,

(ix) ability to provide all five filter responses in all four modes of operation,

(x) low output impedance for MISO (VM and TIM),

(xi) availability of explicit current output for MISO (CM and TAM),

(xii) no requirement for double/negative input signals (voltage/current) in MISO configuration,

(xiii) test natural frequency,

(xiv) inbuilt tunability.

A detailed comparison of the state-of-the-art mixed-mode filters with the proposed design is presented in Table 1.

It can be inferred from the table that the filter structures [16, 19-26, 28-30, 32, 34] employ three or more ABBs for the design. The designs in $[16,28,29,33,34]$ utilize seven or more passive components. The design in [29] requires capacitive matching, which is undesirable in today's submicron technologies. In filters [16-17, 21, 22, 26, 28-30, 32] the quality factor cannot be controlled independent of the natural frequency. The filter structures [17-22, 25, 27, 34] are not truly universal mixed-modes since they cannot realize all five filter responses in VM, CM, TAM and TIM operation. None of the above mixed-mode filters except [20] is designed at natural frequency higher than $4 \mathrm{MHz}$. The filter structures $[16-18,20,23,27-29,33,34]$ lack inbuilt tunability. None of the existing filters (with the exception of [33]) can work in both MISO and SIMO configurations and provide all five filter responses in all Four modes of operation. In addition, some other drawbacks of the design [33] are: (i) the design is not modular as it uses two different ABBs, namely FDCCII and DDCC, also it requires five input voltages and six input currents in MISO configuration, (ii) both capacitors are connected to $X$ terminals which is undesired as it effects the high frequency performance as shown in [35], (iii) use negative and double inputs in MISO configuration, and (iv) lack of built-in tunability. The literature survey points out that although many exemplary mixed-mode filter designs exists, the research in the mix-mode filter design is still limited and newer designs need to be developed to cater to increasing demand of mixed-signal processing systems. In context, this paper aims to introduce a novel mixed-mode filter structure composed of two extra X current conveyor transconductance amplifier (EXCCTA), one switch, two ca- pacitors, and four resistors, which employs only three input current/voltage signals in MISO operation and is free from the above drawbacks of [33]. The striking features of the proposed filter are: (i) provides all five filter responses in all four modes of operation, (ii) it can work in both MISO and SIMO configuration without change in topology, (iii) it has inbuilt tunability, and (iv) the filter exhibits low active and passive sensitivities to passive elements. Beside these the filter enjoys all the properties mentioned in Table 1. The precise design, layout and simulation of the EXCCTA, is done in

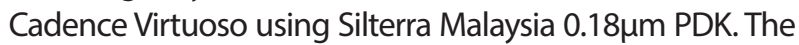
layout verification and parasitic extraction is carried out using Mentor Graphics Calibre. The post layout results bear close resemblance with the theoretical predictions.

\section{Extra $X$ current conveyor transconductance amplifier (EXCCTA)}

The EXCCTA is a versatile electronically tunable ABB carrying features of extra $X$ current conveyor (EXCCII) [13] and operational transconductance amplifier (OTA) [14] in one compact integrated circuit implementation. The EXCCTA provides two independent low impedance current input terminals $X_{p, N}$ together with a high impedance voltage input terminal $Y$. It also has OTA at the output stage imparting tunability to the structure. The block diagram and voltage-current relations of the EXCCTA are given in Figure 1 and Equation (1), respectively. The complete CMOS implementation [15] is presented in Figure 2. The class $A B$ output stage is utilized in the first stage to minimize supply voltage and power dissipation.



Figure 1: Block diagram of EXCCTA

$$
\left[\begin{array}{c}
I_{Y} \\
V_{X P} \\
V_{X N} \\
I_{Z P+} \\
I_{Z P-} \\
I_{Z N+} \\
I_{Z N-} \\
I_{O \pm}
\end{array}\right]=\left[\begin{array}{cccccccc}
0 & 0 & 0 & 0 & 0 & 0 & 0 & 0 \\
1 & 0 & 0 & 0 & 0 & 0 & 0 & 0 \\
1 & 0 & 0 & 0 & 0 & 0 & 0 & 0 \\
0 & 1 & 0 & 0 & 0 & 0 & 0 & 0 \\
0 & -1 & 0 & 0 & 0 & 0 & 0 & 0 \\
0 & 0 & 1 & 0 & 0 & 0 & 0 & 0 \\
0 & 0 & -1 & 0 & 0 & 0 & 0 & 0 \\
0 & 0 & 0 & \pm g_{m} & 0 & 0 & 0 & 0
\end{array}\right]\left[\begin{array}{c}
V_{Y} \\
I_{X P} \\
I_{X N} \\
V_{Z P+} \\
V_{Z P-} \\
V_{Z N+} \\
V_{Z N-} \\
V_{O \pm}
\end{array}\right]
$$






Figure 2: CMOS implementation of the EXCCTA

The number of current output terminals $\left(\mathrm{I}_{\mathrm{ZP}+}, \mathrm{I}_{\mathrm{ZP}-{ }^{\prime}} \mathrm{I}_{\mathrm{ZN}+^{\prime}}\right.$ $\mathrm{I}_{\mathrm{ZN}-\mathrm{I}^{\prime}+} \mathrm{I}_{0-}$ ) can be increased by simply adding two MOS transistors.

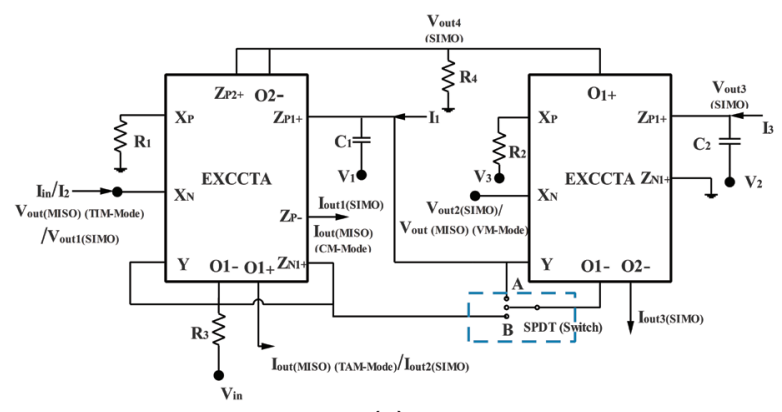

(a)



(b)



(c)

Figure 3: Proposed mix-mode filter: (a) generalized diagram, (b) SIMO configuration, (c) MISO configuration

\section{Proposed electronically tunable mixed-mode universal filter}

The proposed mixed-mode universal filter is presented in Figure 3. The filter employs four resistors, two capacitors, and two EXCCTAs. The filter can work in both SIMO and MISO configurations by adding a single pole double throw (SPDT) switch. The operation and features of the filter in each configuration are discussed below.

\subsection{SIMO configuration}

In SIMO configuration, the currents $I_{1}$ to $I_{3}$ and input voltages $V_{1}$ to $V_{3}$ are set to zero. This grounds all the passive components except $\mathrm{R}_{3}$ as can be inferred from Figure 3(b). In addition, in SIMO configuration no switch is needed for generating filter responses in all four modes. In SIMO configuration the filter has following attributes: (i) inbuilt tunability, (ii) use of grounded capacitors and no capacitive matching requirement, (iii) high input impedance in CM and TIM, (iv) CM and TAM output available form explicit high impedance nodes, ( $v$ ) tunability of $Q$ independent of $\omega_{0^{\prime}}$ (vi) AP gain tunability in VM and TIM, and (vii) availability of all filter function in all four mode.

\subsubsection{SIMO voltage-mode and transadmittance-mode op- eration}

To obtain VM and TAM responses, the input current $I_{\text {in }}$ is set to zero and the input voltage $V_{\text {in }}$ is applied as shown in Figure 3(b). The routine analysis of the circuit leads to the transfer functions as given in Equations (2-6). The VM responses are obtained from terminals $V_{\text {out1(IIMO) }}$ to $\mathrm{V}_{\text {out(4IIMO) }}$ as follows:

$$
T_{V M_{L P}}(s)=\frac{V_{\text {out } 3(S I M O)}(s)}{V_{\text {in }}(s)}=\frac{1}{s^{2} C_{1} C_{2} R_{1} R_{2}+s C_{2} g_{m 1} R_{2} R_{3}+g_{m 2} R_{3}}(2)
$$




$$
\begin{aligned}
T_{V M_{H P}}(s) & =\frac{V_{\text {out } 1(\text { SIMO })}(s)}{V_{\text {in }}(s)}= \\
& =\frac{s^{2} C_{1} C_{2} R_{1} R_{2}}{s^{2} C_{1} C_{2} R_{1} R_{2}+s C_{2} g_{m 1} R_{2} R_{3}+g_{m 2} R_{3}} \\
T_{V M_{B P}}(s) & =\frac{V_{\text {out } 2(\text { SIMO })}(s)}{V_{\text {in }}(s)}= \\
& =\frac{s C_{2} R_{2}}{s^{2} C_{1} C_{2} R_{1} R_{2}+s C_{2} g_{m 1} R_{2} R_{3}+g_{m 2} R_{3}}
\end{aligned}
$$

To obtain unity gain AP response a simple resistive matching of $R_{1}=R_{3}$ is required and the response is obtained across resistor $R_{4}$.

$$
\begin{aligned}
T_{V M_{A P}}(s) & =\frac{V_{\text {out } 4(\text { SIMO })}(s)}{V_{\text {in }}(s)}= \\
& =\frac{R_{4}\left(s^{2} C_{1} C_{2} R_{2}-s C_{2} g_{m 1} R_{2}+g_{m 2}\right)}{s^{2} C_{1} C_{2} R_{1} R_{2}+s C_{2} g_{m 1} R_{2} R_{3}+g_{m 2} R_{3}}
\end{aligned}
$$

If the $\mathrm{O} 2$ - terminal is disconnected from the resistor $\mathrm{R}_{4^{\prime}}$ Equation (5) turns to:

$$
\begin{aligned}
T_{V M_{B R}}(s) & =\frac{V_{\text {out } 4(\operatorname{SIMO})}(s)}{V_{\text {in }}(s)}= \\
& =\frac{s^{2} C_{1} C_{2} R_{2} R_{4}+g_{m 2} R_{4}}{s^{2} C_{1} C_{2} R_{1} R_{2}+s C_{2} g_{m 1} R_{2} R_{3}+g_{m 2} R_{3}}
\end{aligned}
$$

and a $B R$ response is obtained.

The TAM responses are obtained from high impedance $\mathrm{I}_{\text {out1(SIMO) }}$ to $\mathrm{I}_{\text {out3(SIMO) }}$ terminals. The transfer functions are given in Equations (7-11).

$$
\begin{aligned}
T_{T A M_{L P}}(s)= & \frac{I_{\text {out } 3(\operatorname{SIMO})}(s)}{V_{\text {in }}(s)}= \\
= & -\frac{g_{m 2}}{s^{2} C_{1} C_{2} R_{1} R_{2}+s C_{2} g_{m 1} R_{2} R_{3}+g_{m 2} R_{3}} \\
T_{\text {TAM }}(s)= & \frac{I_{\text {out } 1(\operatorname{SIMO})}(s)}{V_{\text {in }}(s)}= \\
& -\frac{s^{2} C_{1} C_{2} R_{2}}{s^{2} C_{1} C_{2} R_{1} R_{2}+s C_{2} g_{m 1} R_{2} R_{3}+g_{m 2} R_{3}}
\end{aligned}
$$

$$
\begin{aligned}
& T_{T_{A A M_{B P}}}(s)=\frac{I_{\text {out } 2(\operatorname{SIMO})}(s)}{V_{\text {in }}(s)}= \\
& =\frac{s C_{2} R_{2} g_{m 1}}{s^{2} C_{1} C_{2} R_{1} R_{2}+s C_{2} R_{2} g_{m 1} R_{3}+g_{m 2} R_{3}} \\
& T_{T A M_{B R}}(s)=\frac{I_{\text {out } 1(\operatorname{SIMO})}(s)+I_{\text {out } 3(\operatorname{SIMO})}(s)}{V_{\text {in }}(s)}= \\
& -\frac{s^{2} C_{1} C_{2} R_{2}+g_{m 2}}{s^{2} C_{1} C_{2} R_{1} R_{2}+s C_{2} g_{m 1} R_{2} R_{3}+g_{m 2} R_{3}} \\
& T_{\text {TAM }}(s)=\frac{I_{\text {out } 1(\text { SIMO })}(s)+I_{\text {out } 2(\operatorname{SIMO})}(s)+I_{\text {out } 3(\operatorname{SIMO})}(s)}{V_{\text {in }}(s)}= \\
& -\frac{s^{2} C_{1} C_{2} R_{2}-s C_{2} R_{2} g_{m 1}+g_{m 2}}{s^{2} C_{1} C_{2} R_{1} R_{2}+s C_{2} g_{m 1} R_{2} R_{3}+g_{m 2} R_{3}} .
\end{aligned}
$$

In TAM, the BR and AP responses can be obtained by appropriately connecting the HP, LP and BP currents. It must be pointed out that, if the filter is designed to work in SIMO configuration then there is no need for the SPDT switch.

\subsubsection{SIMO current-mode and transimpedance-mode op- eration}

To obtain CM and TIM response, input voltage $V_{\text {in }}$ is set to zero and the input current $I_{\text {in }}$ is applied to the filter. In CM operation all passive elements are grounded. The $\mathrm{CM}$ responses are available from high impedance terminals $I_{\text {out (SIMO) }}$ to $I_{\text {out3(SIMO) }}$ and TIM responses are obtained from terminals $V_{\text {out (SIMO) }}$ to $V_{\text {out4(SIMO) }}$. The CM filter transfer functions are given in Equations (12-16). In CM, the $\mathrm{BR}$ and $\mathrm{AP}$ responses can be obtained by appropriately summing the output currents $\left(I_{H P} I_{L^{P}} I_{B P}\right)$.

$$
\begin{aligned}
T_{C M_{H P}}(s) & =\frac{I_{\text {out } 1(\text { SIMO })}(s)}{I_{\text {in }}(s)}= \\
& =\frac{s^{2} C_{1} C_{2} R_{2} R_{3}}{s^{2} C_{1} C_{2} R_{1} R_{2}+s C_{2} g_{m 1} R_{2} R_{3}+g_{m 2} R_{3}} \\
T_{C M_{B P}}(s) & =\frac{I_{\text {out } 2(\text { SIMO })}(s)}{I_{\text {in }}(s)}= \\
& =\frac{-s C_{2} g_{m 1} R_{2} R_{3}}{s^{2} C_{1} C_{2} R_{1} R_{2}+s C_{2} g_{m 1} R_{2} R_{3}+g_{m 2} R_{3}}
\end{aligned}
$$




$$
\begin{aligned}
T_{C M_{L P}}(s) & =\frac{I_{\text {out } 3(\operatorname{SIMO})}(s)}{I_{\text {in }}(s)}= \\
& =\frac{g_{m 2} R_{3}}{s^{2} C_{1} C_{2} R_{1} R_{2}+s C_{2} g_{m 1} R_{2} R_{3}+g_{m 2} R_{3}} \\
T_{C M_{B R}}(s) & =\frac{I_{\text {out } 1(\operatorname{SIMO})}(s)+I_{\text {out } 3(\operatorname{SIMO})}(s)}{I_{\text {in }}(s)}= \\
& =\frac{R_{3}\left(s^{2} C_{1} C_{2} R_{2}+g_{m 2}\right)}{s^{2} C_{1} C_{2} R_{1} R_{2}+s C_{2} g_{m 1} R_{2} R_{3}+g_{m 2} R_{3}} \\
T_{C M_{A P}}(s) & =\frac{I_{\text {out } 1(S I M O)}(s)+I_{\text {out } 2(S I M O)}(s)+I_{\text {out } 3(\operatorname{SIMO})}(s)}{I_{\text {in }}(s)}= \\
& =\frac{R_{3}\left(s^{2} C_{1} C_{2} R_{2}-s C_{2} g_{m 1} R_{2}+g_{m 2}\right)}{s^{2} C_{1} C_{2} R_{1} R_{2}+s C_{2} g_{m 1} R_{2} R_{3}+g_{m 2} R_{3}}
\end{aligned}
$$

The TIM filter transfer functions are given in Equations (17-21) as follows:

$$
\begin{aligned}
T_{T I M_{H P}}(s)= & \frac{V_{\text {out } 1(\text { SIMO) }}(s)}{I_{\text {in }}(s)}= \\
& -\frac{s^{2} C_{1} C_{2} R_{1} R_{2} R_{3}}{s^{2} C_{1} C_{2} R_{1} R_{2}+s C_{2} g_{m 1} R_{2} R_{3}+g_{m 2} R_{3}} \\
T_{T I M_{B P}}(s)= & \frac{V_{\text {out } 2(S I M O)}(s)}{I_{\text {in }}(s)}= \\
& -\frac{s C_{2} R_{2} R_{3}}{s^{2} C_{1} C_{2} R_{1} R_{2}+s C_{2} g_{m 1} R_{2} R_{3}+g_{m 2} R_{3}} \\
T_{T I M_{L P}}(s)= & \frac{V_{\text {out } 3(S I M O)}(s)}{I_{\text {in }}(s)}= \\
& -\frac{R_{3}}{s^{2} C_{1} C_{2} R_{1} R_{2}+s C_{2} g_{m 1} R_{2} R_{3}+g_{m 2} R_{3}}
\end{aligned}
$$

Note that to obtain unity gain AP response a simple resistive matching of $R_{1}=R_{3}$ is required and the response is obtained across resistor $R_{4}$ :

$$
\begin{aligned}
T_{T I M_{A P}}(s)= & \frac{V_{\text {out } 4(\operatorname{SIMO})}(s)}{I_{\text {in }}(s)}= \\
& -\frac{R_{3} R_{4}\left(s^{2} C_{1} C_{2} R_{2}-s C_{2} R_{2} g_{m 1}+1\right)}{s^{2} C_{1} C_{2} R_{1} R_{2}+s C_{2} g_{m 1} R_{2} R_{3}+g_{m 2} R_{3}}
\end{aligned}
$$

while $\mathrm{BR}$ response is obtained, if the $\mathrm{O} 2$ - terminal is disconnected from resistor $\mathrm{R}_{4}$ :

$$
\begin{aligned}
T_{T I M_{B R}}(s)= & \frac{V_{\text {out } 4(\operatorname{SIMO})}(s)}{I_{\text {in }}(s)}= \\
& -\frac{R_{3} R_{4}\left(g_{m 2}+s^{2} C_{1} C_{2} R_{2}\right)}{s^{2} C_{1} C_{2} R_{1} R_{2}+s C_{2} g_{m 1} R_{2} R_{3}+g_{m 2} R_{3}}
\end{aligned}
$$

Subsequently, the expression for natural frequency and $Q$ of the SIMO mixed-mode filter are:

$$
\begin{aligned}
& f_{0}=\frac{1}{2 \pi} \sqrt{\frac{g_{m 2} R_{3}}{C_{1} C_{2} R_{1} R_{2}}} \\
& Q=\frac{1}{g_{m 1}} \sqrt{\frac{C_{1} g_{m 2} R_{1}}{C_{2} R_{2} R_{3}}}
\end{aligned}
$$

\subsection{MISO configuration}

In MISO configuration, the input current $I_{\text {in }}$ and input voltage $V_{\text {in }}$ are set to zero. The input currents $I_{1}$ to $I_{3}$ and input voltages $V_{1}$ to $V_{3}$ are applied to obtain the required filter responses. In this configuration only three resistors are employed, resistor $\mathrm{R}_{4}$ is not required and can be eliminated as shown in Figure 3(c). The attractive features of the filter include: (i) low output impedance for VM and TIM, (ii) high output impedance explicit current output for CM and TAM, (iii) no requirement for double/negative input signals (voltage/current), (iv) tunability, (v) simultaneous availability of VM and TIM/ CM and TAM responses from same input sequence, and (vi) filter is cascadable in all four modes. The operation of the filter is described below.

\subsubsection{MISO voltage-mode and transadmittance-mode op- eration}

To obtain VM and TAM responses, the input voltage $V_{1}$ to $V_{3}$ are applied according to the Table 2 and the SPDT switch is connected to point $B$.

Table 2: Input voltage excitation sequence

\begin{tabular}{|l|c|c|c|c|c|} 
Response & \multicolumn{3}{|c|}{ Inputs } & $\begin{array}{c}\text { Passive } \\
\text { Matching } \\
\text { Condition }\end{array}$ & $\begin{array}{c}\text { Active } \\
\text { Matching }\end{array}$ \\
\hline & $V_{1}$ & $V_{2}$ & $V_{3}$ & & \\
\hline LP & 0 & 0 & 1 & No & No \\
\hline HP & 1 & 0 & 0 & No & No \\
\hline BP & 0 & 1 & 0 & No & No \\
\hline BR & 1 & 0 & 1 & No & No \\
\hline AP & 1 & 1 & 1 & No & $g_{m 1}=g_{m 2}$ \\
\hline
\end{tabular}


The output responses are obtained from low impedance terminal $\mathrm{V}_{\text {out(MISO)(VM-Mode) }}$ and high impedance terminal out(MISO)(TAM-Mode) $_{\text {The transfer functions for VM and }}$ TAM modes are given as:

$$
\begin{aligned}
& V_{\text {out }(\text { MISO })(V M-M o d e)}= \\
& =\frac{s^{2} C_{1} C_{2} R_{1} R_{2} V_{1}-s C_{2} g_{m 2} R_{2} R_{3} V_{2}+g_{m 2} R_{3} V_{3}}{s^{2} C_{1} C_{2} R_{1} R_{2}+s C_{2} g_{m 1} R_{2} R_{3}+g_{m 2} R_{3}} \\
& I_{\text {out }(\text { MISO })(\text { TAM-Mode })}= \\
& =g_{m 1}\left[\frac{s^{2} C_{1} C_{2} R_{1} R_{2} V_{1}-s C_{2} g_{m 2} R_{2} R_{3} V_{2}+g_{m 2} R_{3} V_{3}}{s^{2} C_{1} C_{2} R_{1} R_{2}+s C_{2} g_{m 1} R_{2} R_{3}+g_{m 2} R_{3}}\right]
\end{aligned}
$$

while $f_{0}$ and $Q$ correspond to Equations (22) and (23), respectively.

\subsubsection{MISO current-mode and transimpedance-mode op-} eration

To obtain CM and TIM responses, the input voltages $V_{1}$ to $V_{3}$ are set to zero, the SPDT switch is connected to point $A$, and input current signals $I_{1}$ to $I_{3}$ are applied according to Table 3.

Table 3: Input current excitation sequence

\begin{tabular}{|l|c|c|c|c|c|} 
Response & \multicolumn{3}{|c|}{ Inputs } & $\begin{array}{c}\text { Passive } \\
\text { Matching } \\
\text { Condition }\end{array}$ & $\begin{array}{c}\text { Active } \\
\text { Matching }\end{array}$ \\
\hline & \multicolumn{7}{|c|}{$\mathrm{I}_{1}$} & $\mathrm{I}_{2}$ & $\mathrm{I}_{3}$ & & \\
\hline LP & 0 & 0 & 1 & No & No \\
\hline HP & 0 & 1 & 1 & No & $\mathrm{g}_{\mathrm{m} 1} \mathrm{R}_{2}=1$ \\
\hline BP & 1 & 0 & 0 & No & No \\
\hline BR & 0 & 1 & 0 & No & No \\
\hline AP & 1 & 1 & 0 & $\mathrm{R}_{3}=\mathrm{R}_{1}$ & No \\
\hline
\end{tabular}

The $\mathrm{CM}$ responses are obtained from high impedance terminal I out(MISO)(CM-Mode) and TIM responses from low impedance terminal $\mathrm{V}_{\text {out(MISO)(TIM-Mode) }}$. The transfer functions and expression for quality factor and pole frequency are given as:

$$
\begin{aligned}
& I_{\text {out }(\text { MISO })(\text { CM-Mode })}= \\
& =\left[\frac{s C_{2} R_{2} g_{m 1} R_{3} I_{1}-\left(s^{2} C_{1} C_{2} R_{2} R_{3}+g_{m 2} R_{3}\right) I_{2}+g_{m 1} g_{m 2} R_{2} R_{3} I_{3}}{s^{2} C_{1} C_{2} R_{1} R_{2}+s C_{2} g_{m 1} R_{2} R_{3}+g_{m 2} R_{1}}\right] \text { (28) } \\
& V_{\text {out }(\text { MISO)(TIM-Mode })}= \\
& =R_{1} R_{3}\left[\frac{s C_{2} g_{m 1} R_{2} I_{1}-\left(s^{2} C_{1} C_{2} R_{2}+g_{m 2}\right) I_{2}+g_{m 1} g_{m 2} R_{2} I_{3}}{s^{2} C_{1} C_{2} R_{1} R_{2}+s C_{2} g_{m 1} R_{2} R_{3}+g_{m 2} R_{1}}\right] \text { (29) }
\end{aligned}
$$

$$
\begin{aligned}
& f_{0}=\frac{1}{2 \pi} \sqrt{\frac{g_{m 2}}{C_{1} C_{2} R_{2}}} \\
& Q=\frac{R_{1}}{g_{m 1} R_{3}} \sqrt{\frac{C_{1} g_{m 2}}{C_{2} R_{2}}}
\end{aligned}
$$

Note that except for AP there is no requirement for matching passive components. In case of HP response, the value of transconductance $g_{m 1}$ should be adjusted to achieve $g_{m 1} R_{2}=1$, which can be easily accomplished by adjusting the bias current $\mathrm{I}_{\text {bias }}$ of the first EXCCTA.

As a brief conclusion it must be emphasised that the proposed filter can realize SIMO (all modes) and MISO (VM and TAM) responses without requiring any switch. The switch is only required to obtain MISO (CM and TIM) responses.

\section{Non-Ideal and sensitivity analysis}

The non-ideal model of the EXCCTA is presented in Figure 4. As can be deduced, the various parasitic resistances and capacitances appear in parallel with the input and output nodes of the device. The low impedance $X$ node has a parasitic resistance and inductance in series with it. The other non-ideal effects that influences the response of the EXCCTA are the frequency dependent non-ideal current $\left(a_{p}, a_{N}\right)$, voltage $\left(\beta_{p}, \beta_{N}\right)$, and OTA transconductance transfer $\left(\gamma, \gamma^{\prime}\right)$ gains. These gains cause a change in the current and voltage signals during transfer leading to undesired response.



Figure 4: Non-ideal model of EXCCTA with parasitics

Taking into account the non-ideal gains the V-I characteristics of the EXCCTA in (1) will be modified as follows: $I_{Y}=0, V_{X P}=\beta_{P} V_{Y^{\prime}} V_{X N}=\beta_{N} V_{Y^{\prime}} I_{Z P} \quad{ }_{P} I_{X P^{\prime}}$ 
$I_{Z P-}=\alpha_{P}^{\prime} I_{X P}, I_{Z N+}=\alpha_{N} I_{X N}, I_{Z N-}=\alpha_{N}^{\prime} I_{X N} I_{O+}=\gamma g_{m} V_{Z P+}$,

$I_{O-}=-\gamma^{\prime} g_{m} V_{Z P+}$, where $\beta_{P m}=1-\varepsilon_{v P m}, \beta_{N m}=1-\varepsilon_{v N m}$,

$\alpha_{P m}=1-\varepsilon_{i P m}, \alpha_{P m}^{\prime}=1-\varepsilon_{i P m}^{\prime}, \alpha_{N m}=1-\varepsilon_{i N m}, \alpha_{N m}^{\prime}=1-\varepsilon_{i N m}^{\prime}$, $\gamma_{m}=1-\varepsilon_{g_{m} m}$ and $\gamma_{m}^{\prime}=1-\varepsilon_{g_{m} m}^{\prime}$ for $m=1,2$, which refers to the number of EXCCTAs. Here, $\varepsilon_{v P m}$ and $\varepsilon_{v N m}\left(\left|\varepsilon_{v P m}\right|,\left|\varepsilon_{v N m}\right| \ll 1\right)$ denote voltage tracking errors, $\varepsilon_{i P m}, \dot{\varepsilon}_{i P m}^{\prime}, \varepsilon_{i N m}, \varepsilon_{i N m}^{\prime}\left(\left|\varepsilon_{i P m}\right|,\left|\varepsilon_{i P m}^{\prime}\right|,\left|\varepsilon_{i N m}\right|,\left|\varepsilon_{i N m}^{\prime}\right| \ll 1\right)$ denote current tracking errors, and $\varepsilon_{g_{m} m^{\prime}}, \varepsilon_{g_{m} m}^{\prime}\left(\left|\varepsilon_{g_{m} m}\right|,\left|\varepsilon_{g_{m} m}^{\prime}\right| \ll 1\right)$ denote transconductance errors of the EXCCTA.

The non-ideal analysis considering the effect of nonideal current, voltage, and transconductance transfer gains is carried out for SIMO (VM and CM) and MISO (VM and CM) configurations to see its effect on the transfer function, $f_{0^{\prime}}$ and $Q$ of the proposed filters. The modified expressions of filter transfer functions, $f_{0^{\prime}}$ and $Q$ for the SIMO, and MISO configurations are presented in Equations (32-44).

$$
\begin{aligned}
& f_{0[\text { MISO }(\text { CM\&TIM })]}^{\prime}=\frac{1}{2 \pi} \sqrt{\frac{\gamma_{2}^{\prime} \alpha_{P 2} \beta_{P 2} g_{m 2}}{C_{1} C_{2} R_{2}}} \\
& Q_{[\text {MISO }(\text { CM\&TIM })]}^{\prime}=\frac{R_{1}}{\alpha_{P 1} \beta_{P 1} \gamma_{1}^{\prime} g_{m 1} R_{3}} \sqrt{\frac{\gamma_{2}^{\prime} \alpha_{P 2} \beta_{P 2} C_{1} g_{m 2}}{C_{2} R_{2}}}
\end{aligned}
$$

As a result of component tolerance and non-idealities in EXCCTA the response of the practical filter deviates from the ideal one. To get a measure of the deviation, the relative sensitivity is applied. Mathematically, relative sensitivity is defined as $S_{x}^{y}=\lim _{\Delta x \rightarrow \infty}\left\{\frac{\Delta y}{\Delta x / y}\right\}=\frac{x}{y} \frac{\partial y}{\partial x}$, where $\mathrm{x}$ is the component that is varied and $y$ is the $\omega_{0}$ and $Q$ in our case.

The sensitivities of $\omega_{0}$ and $Q$ with respect to the nonideal gains and passive components are given below.

$$
\begin{aligned}
& T_{V M_{L P}}^{\prime}(s)=\frac{\alpha_{P 1} \beta_{P 1} \alpha_{P 2} \beta_{P 2}}{s^{2} C_{1} C_{2} R_{1} R_{2}+s C_{2} g_{m 1} R_{2} R_{3} \gamma_{1}^{\prime} \alpha_{P 1} \beta_{P 1}+g_{m 2} R_{3} \gamma_{2}^{\prime} \alpha_{P 1} \beta_{P 1} \alpha_{P 2} \beta_{P 2}} \\
& T_{V M_{H P}}^{\prime}(s)=\frac{s^{2} C_{1} C_{2} R_{1} R_{2}}{s^{2} C_{1} C_{2} R_{1} R_{2}+s C_{2} g_{m 1} R_{2} R_{3} \gamma_{1}^{\prime} \alpha_{P 1} \beta_{P 1}+g_{m 2} R_{3} \gamma_{2}^{\prime} \alpha_{P 1} \beta_{P 1} \alpha_{P 2} \beta_{P 2}} \\
& T_{V M_{B P}}^{\prime}(s)=\frac{s C_{2} R_{2} \alpha_{P 1} \beta_{P 1}}{s^{2} C_{1} C_{2} R_{1} R_{2}+s C_{2} g_{m 1} R_{2} R_{3} \gamma_{1}^{\prime} \alpha_{P 1} \beta_{P 1}+g_{m 2} R_{3} \gamma_{2}^{\prime} \alpha_{P 1} \beta_{P 1} \alpha_{P 2} \beta_{P 2}} \\
& T_{V M_{A P}}^{\prime}(s)=\frac{R_{4}\left(s^{2} C_{1} C_{2}^{\prime} R_{2} \alpha_{P 1} \beta_{P 1}-s C_{2} R_{2} \gamma_{1}^{\prime} g_{m 1} \alpha_{P 1} \beta_{P 1}+\gamma_{2}^{\prime} g_{m 2} \alpha_{P 1} \beta_{P 1} \alpha_{P 2} \beta_{P 2}\right)}{s^{2} C_{1} C_{2} R_{1} R_{2}+s C_{2} g_{m 1} R_{2} R_{3} \gamma_{1}^{\prime} \alpha_{P 1} \beta_{P 1}+g_{m 2} R_{3} \gamma_{2}^{\prime} \alpha_{P 1} \beta_{P 1} \alpha_{P 2} \beta_{P 2}} \\
& T_{C M_{L P}}^{\prime}(s)=\frac{g_{m 2} R_{3} \alpha_{N 1} \gamma_{2}^{\prime} \alpha_{P 1} \beta_{P 1} \alpha_{P 2} \beta_{P 2}}{s^{2} C_{1} C_{2} R_{1} R_{2}+s C_{2} g_{m 1} R_{2} R_{3} \gamma_{1}^{\prime} \alpha_{P 1} \beta_{P 1}+g_{m 2} R_{3} \gamma_{2}^{\prime} \alpha_{P 1} \beta_{P 1} \alpha_{P 2} \beta_{P 2}} \\
& T_{C M_{H P}}^{\prime}(s)=\frac{s^{2} C_{1} C_{2} R_{3} R_{2} \beta_{P 1} \alpha_{N 1}}{s^{2} C_{1} C_{2} R_{1} R_{2}+s C_{2} g_{m 1} R_{2} R_{3} \gamma_{1}^{\prime} \alpha_{P 1} \beta_{P 1}+g_{m 2} R_{3} \gamma_{2}^{\prime} \alpha_{P 1} \beta_{P 1} \alpha_{P 2} \beta_{P 2}} \\
& T_{C M_{B P}}^{\prime}(s)=\frac{-s C_{2} R_{2} R_{3} \alpha_{P 1} \beta_{P 1} \alpha_{N 1} \gamma_{1}^{\prime} g_{m 1}}{s^{2} C_{1} C_{2} R_{1} R_{2}+s C_{2} g_{m 1} R_{2} R_{3} \gamma_{1}^{\prime} \alpha_{P 1} \beta_{P 1}+g_{m 2} R_{3} \gamma_{2}^{\prime} \alpha_{P 1} \beta_{P 1} \alpha_{P 2} \beta_{P 2}} \\
& f_{0[S I M O ~ \& ~ M I S O(V M ~ \& T A M)]}^{\prime}=\frac{1}{2 \pi} \sqrt{\frac{\gamma_{2}^{\prime} \alpha_{P 1} \beta_{P 1} \beta_{P 2} g_{m 2} R_{3}}{C_{1} C_{2} R_{1} R_{2} \alpha_{P 2}}} \text { (39) } \\
& Q_{[\text {SIMO \& MISO (VM \&TAM) }]}^{\prime}=\frac{1}{\gamma_{1}^{\prime} g_{m 1}} \sqrt{\frac{\gamma_{2}^{\prime} \beta_{P 2} C_{1} g_{m 2} R_{1}}{C_{2} R_{2} \alpha_{P 1} \alpha_{P 2} \beta_{P 1}}}(40) \\
& V_{\text {out }(\text { MISO })(V M-M o d e)}^{\prime}=\frac{s^{2} C_{1} C_{2} R_{1} R_{2} \alpha_{P 2} V_{1}-s C_{2} g_{m 2} R_{2} R_{3} \gamma_{2}^{\prime} \alpha_{P 1} \beta_{P 1} V_{2}+g_{m 2} R_{3} \gamma_{2}^{\prime} \alpha_{P 1} \beta_{P 1} V_{3}}{s^{2} C_{1} C_{2} R_{1} R_{2} \alpha_{P 2}+s C_{2} g_{m 1} R_{2} R_{3} \gamma_{1}^{\prime} \alpha_{P 2} \alpha_{P 1} \beta_{P 1}+\gamma_{2}^{\prime} \beta_{P 1} \beta_{P 2} \alpha_{P 1} g_{m 2} R_{3}} \\
& I_{\text {out }(\text { MISO })(C M-M o d e)}^{\prime}=\left[\frac{s C_{2} g_{m 1} R_{2} R_{3} \gamma_{1}^{\prime} \alpha_{P 1} \beta_{P 1} I_{1}-\left(s^{2} C_{1} C_{2} R_{3} R_{2} \alpha_{P 1} \beta_{P 1}+g_{m 2} \gamma_{2}^{\prime} R_{3} \alpha_{P 1} \beta_{P 1}\right) I_{2}+\alpha_{P 1} \beta_{P 1} \gamma_{1}^{\prime} \gamma_{2}^{\prime} g_{m 1} g_{m 2} R_{2} R_{3} I_{3}}{s^{2} C_{1} C_{2} R_{1} R_{2}+s C_{2} g_{m 1} R_{2} R_{3} \alpha_{P 1} \beta_{P 1} \gamma_{1}^{\prime}+g_{m 2} R_{1} \alpha_{P 2} \beta_{P 2} \gamma_{2}^{\prime}}\right]
\end{aligned}
$$




$$
\begin{aligned}
& -S_{C_{1}}^{\omega_{0}}=-S_{C_{2}}^{\omega_{0}}=-S_{R_{1}}^{\omega_{0}}=-S_{R_{2}}^{\omega_{0}}=-S_{\alpha_{P_{2}}}^{\omega_{0}}=S_{\gamma_{2}}^{\omega_{0}}= \\
& =S_{\alpha_{P 1}}^{\omega_{0}}=S_{\beta_{P 1}}^{\omega_{0}}=S_{\beta_{P 2}}^{\omega_{0}}=S_{g_{m 2}}^{\omega_{0}}=S_{R_{3}}^{\omega_{0}}=\frac{1}{2} \\
& S_{C_{1}}^{Q}=-S_{C_{2}}^{Q}=S_{R_{1}}^{Q}=-S_{R_{2}}^{Q}=S_{g_{m 2}}^{Q}=-S_{\alpha_{P 1}}^{Q}= \\
& =-S_{\alpha_{P 2}}^{Q}=-S_{\beta_{P 1}}^{Q}=S_{\beta_{P 2}}^{Q}=S_{\gamma_{2}}^{Q}=\frac{1}{2} \\
& S_{\gamma_{1}^{\prime}}^{Q}=S_{g_{m 1}}^{Q}=-1 \\
& -S_{C_{1}}^{\omega_{0}}=-S_{C_{2}}^{\omega_{0}}=-S_{R_{2}}^{\omega_{0}}=S_{\gamma_{2}}^{\omega_{0}}=S_{g_{m 2}}^{\omega_{0}}=S_{\alpha_{P 2}}^{\omega_{0}}=S_{\beta_{P 2}}^{\omega_{0}}=\frac{1}{2}(48) \\
& S_{C_{1}}^{Q}=-S_{R_{2}}^{\omega}=-S_{C_{2}}^{Q}=S_{\alpha_{P 2}}^{Q}=S_{g_{m 2}}^{Q}=S_{\beta_{P_{2}}}^{Q}=S_{\gamma_{2}}^{Q}=\frac{1}{2} \\
& S_{R_{1}}^{Q}=-S_{\alpha_{P 1}}^{Q}=-S_{\beta_{P 1}}^{Q}=-S_{g_{m 1}}^{Q}=-S_{R_{3}}^{Q}=-S_{\gamma_{1}^{\prime}}^{Q}=1
\end{aligned}
$$

The sensitivities are low and have absolute values not higher than unity.

\section{Simulation results}

To validate the proposed mixed-mode filter, the EXCCTA is designed in Cadence Virtuoso software using $0.18 \mu \mathrm{m}$ PDK provided by Silterra Malaysia. The widths and lengths of the MOS transistors are given in Table 4. The supply voltage is set to $\pm 1.25 \mathrm{~V}$ and the bias current of th OTAs is set to $120 \mu \mathrm{A}$ resulting in transconductance of $g_{m 1}=g_{m 2}=1.0321 \mathrm{mS}$. The complete layout of the EXCCTA is designed as presented in Figure 5. The lay- out verification and parasitic extraction are done using Mentor Graphics Calibre verification tool. The high performance nhp and php MOSFETs from the PDK library are employed in the design. The EXCCTA occupied a total chip area of $(52.78 \times 22.085) \mu \mathrm{m}^{2}$.

Table 4: Width and length of the MOS transistors

\begin{tabular}{|l|c|c|} 
Transistor & Width $(\mu \mathrm{m})$ & Length $(\mu \mathrm{m})$ \\
\hline M1-M4 & 3.06 & 0.36 \\
\hline M5-M8 & 4 & 0.36 \\
\hline M9-M11, M19-M21 & 2.16 & 0.36 \\
\hline M12, M13, M22, M23 & 1.08 & 0.72 \\
\hline M14-M18, M24-M28 & 0.72 & 0.72 \\
\hline M29-M32 & 1.8 & 0.36 \\
\hline M33-M36 & 5.4 & 0.36 \\
\hline M37-M40 & 1.8 & 0.72 \\
\hline
\end{tabular}

\subsection{SIMO configuration operation}

First of all, the SIMO configuration of the proposed filter is validated. The filter is designed for centre frequency of $7.622 \mathrm{MHz}$ by setting passive components and OTA bias current values as follows: $R_{1}=1 \mathrm{k} \Omega, R_{2}=$ $2 \mathrm{k} \Omega, R_{3}=1 \mathrm{k} \Omega, \mathrm{R}_{4}=1 \mathrm{k} \Omega, \mathrm{C}_{1}=15 \mathrm{pF}, \mathrm{C}_{2}=15 \mathrm{pF}$, and $g_{m 1}=g_{m 2}=1.0321 \mathrm{mS}$. For the sake of comparison, the EXCCTA based filter responses are plotted along with the ideal filter results obtained using the Matlab software. The VM responses are shown in Figure 6. The AP response is obtained across resistance $R_{4}$. In addition, the gain of the AP response can be tuned through $R_{4}$ without affecting other filter parameters as is evident from Figure 7.

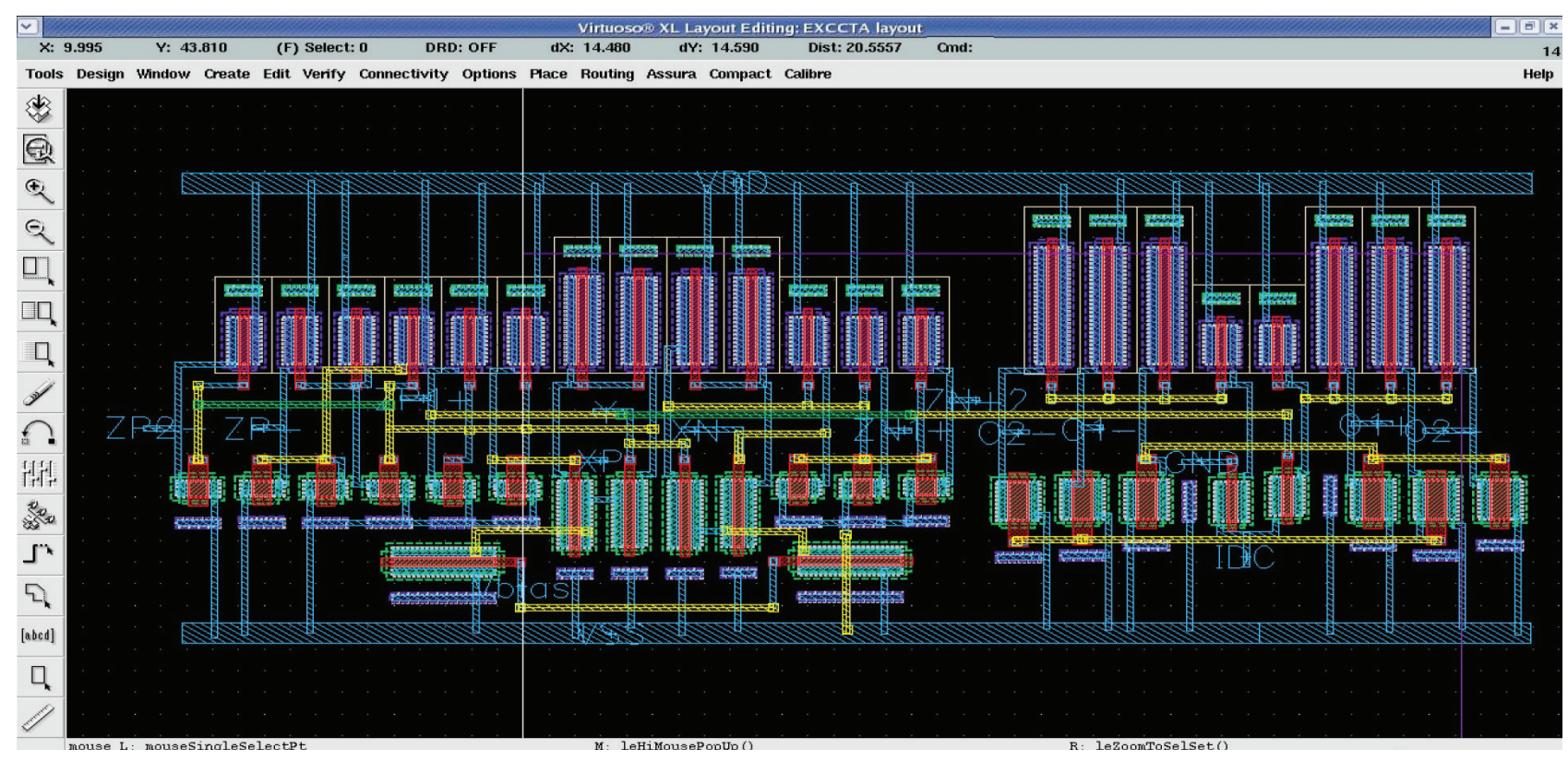

Figure 5: Layout of the EXCCTA used in proposed filter design 


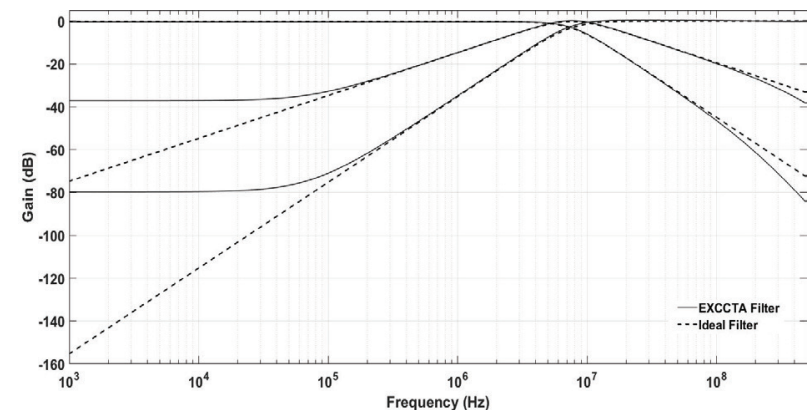

Figure 6: VM SIMO configuration: Frequency responses of the LP, BP, and HP filter

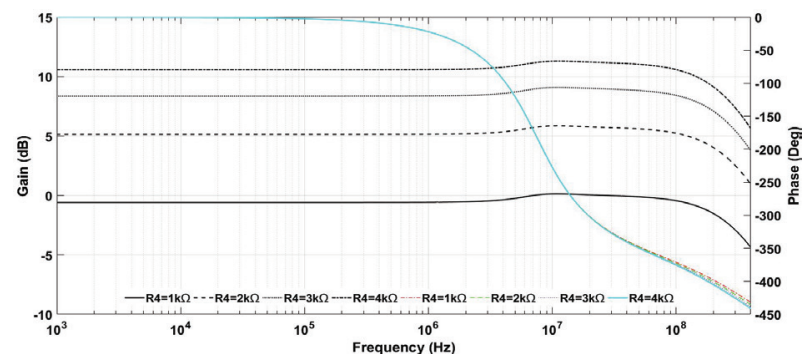

Figure 7: VM SIMO configuration: Gain and phase responses of the AP filter

To analyse the quality factor tuning, the BP response is plotted for different values of $\mathrm{I}_{\text {Bias } 1}$ current of OTA 1 . It can be deduced from Figure 8 that the quality factor can be tuned independent of the centre frequency. The signal processing capability of the VM filter is verified by examining the transient response of the filter. A sinusoidal voltage input signal at $7.622 \mathrm{MHz}$ is applied and the observed LP, BP, HP responses are plotted as given in Figure 9. The total harmonic distortion (THD) of the filter for LP, BP, HP and AP responses is plotted for different input signal amplitudes. The THD remains within acceptable limits for large input range as presented in Figure 10.



Figure 8: VM SIMO configuration: Quality factor tuning for different bias currents in BP filter



Figure 9: VM SIMO configuration: Transient analysis of the filter

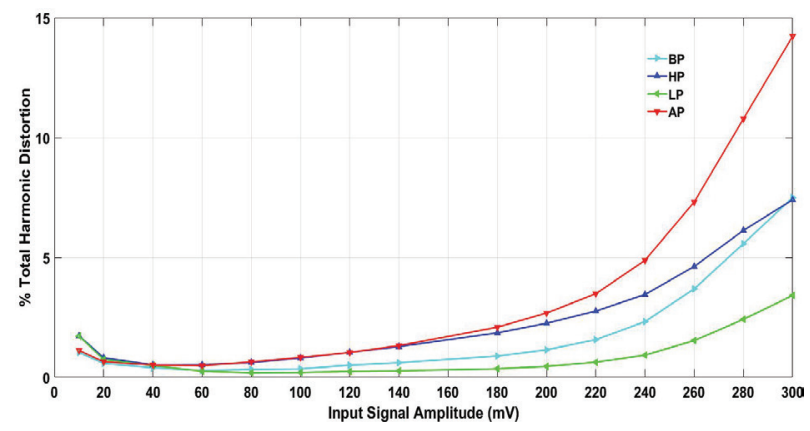

Figure 10: VM SIMO configuration: The THD analysis results of the filter

To study the effect of process variation on the proposed filter Monte Carlo analysis is carried out for $10 \%$ variation in both capacitor $C_{1}$ and $C_{2}$ values for $B P$ response. The analysis is done for 200 runs and the results are presented in Figure 11.

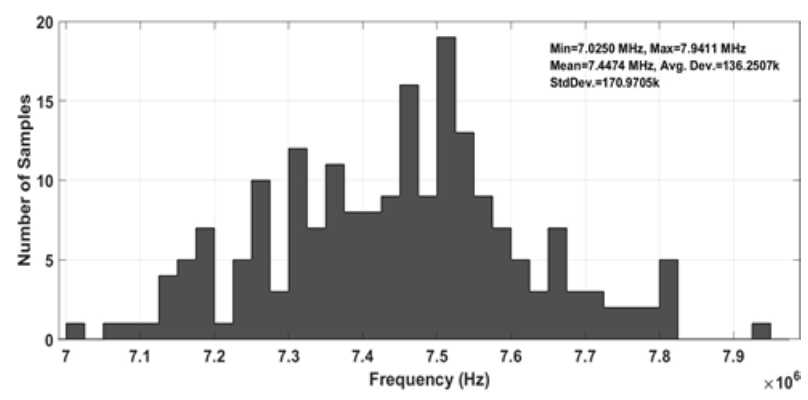

Figure 11: VM SIMO configuration: The Monte Carlo analysis results

The results for CM SIMO filter are presented in Figures 12 and 13 . The BR and AP responses are obtained by summing $\mathrm{I}_{\mathrm{HP}^{\prime}} \mathrm{I}_{\mathrm{LP}}$ and $\mathrm{I}_{\mathrm{BP}}$ currents appropriately as discussed in section 3 . The quality factor variation with OTA1 bias current $I_{\text {Bias1 }}$ is depicted in Figure 14. 


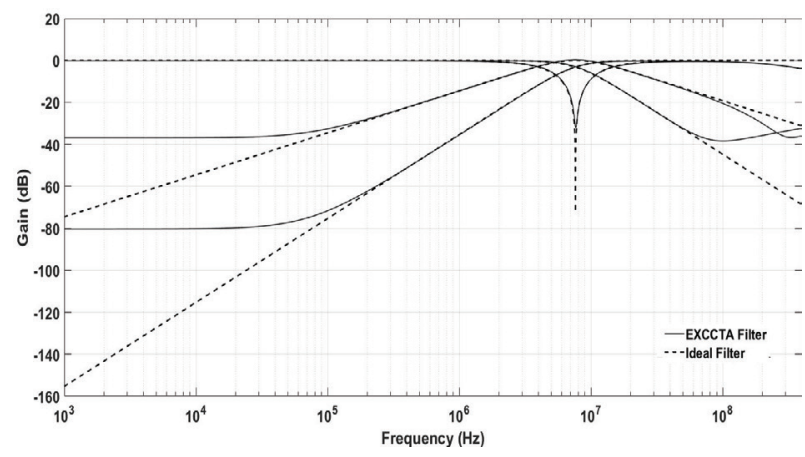

Figure 12: $C M$ SIMO configuration: Frequency responses of the LP, BP, HP, and BR filter

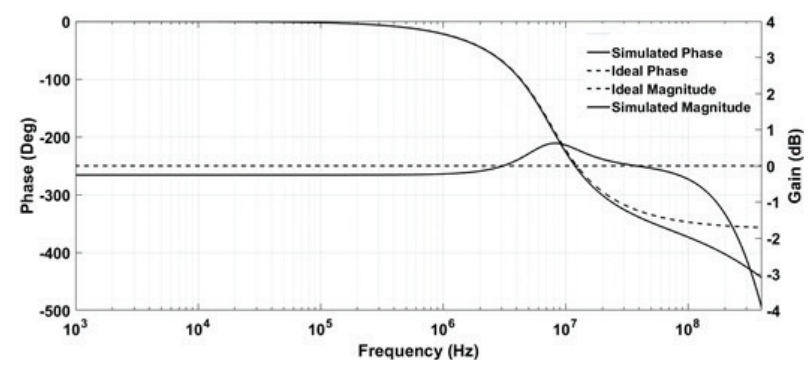

Figure 13: CM SIMO configuration: Gain and phase responses of the AP filter

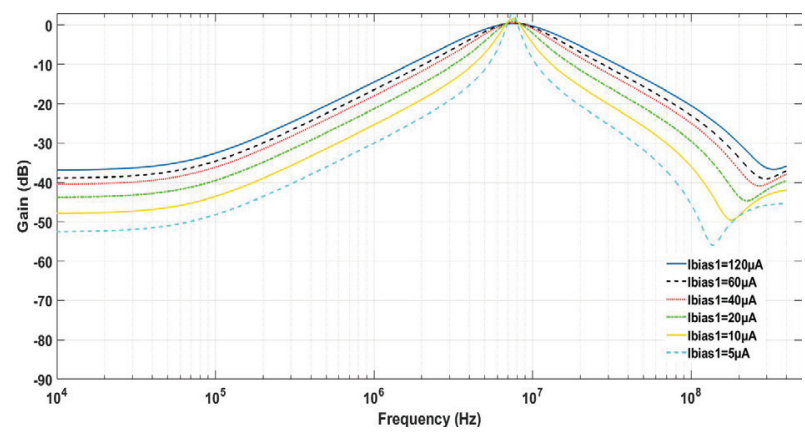

Figure 14: CM SIMO configuration: Quality factor tuning for different bias currents in BP filter

The Monte Carlo analysis is carried out for $10 \%$ variation in both capacitor $C_{1}$ and $C_{2}$ values for $L P$ response in $\mathrm{CM}$ operation. The analysis is done for 200 runs and the results are given in Figures 15. To further see the effect of process variability another Monte Carlo analysis is done using the Monte Carlo parameters given in the product design kit (PDK) for the MOS transistors. The results are presented in Figure 16. As can be deduced the mean value of frequency showed a deviation of approximately $6.1 \%$ for designed frequency. The THD for $L P, H P$, and $B P$ responses are presented in Figure 17.

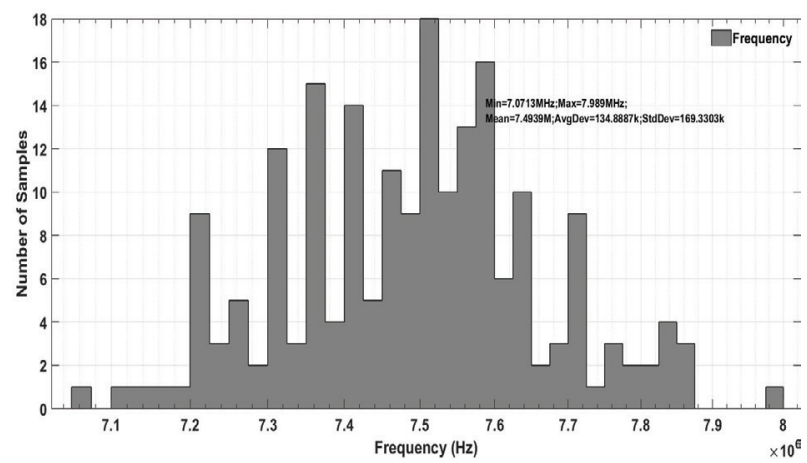

Figure 15: CM SIMO configuration: The Monte Carlo analysis results



Figure 16: CM SIMO configuration: The Monte Carlo analysis results for transistor variability

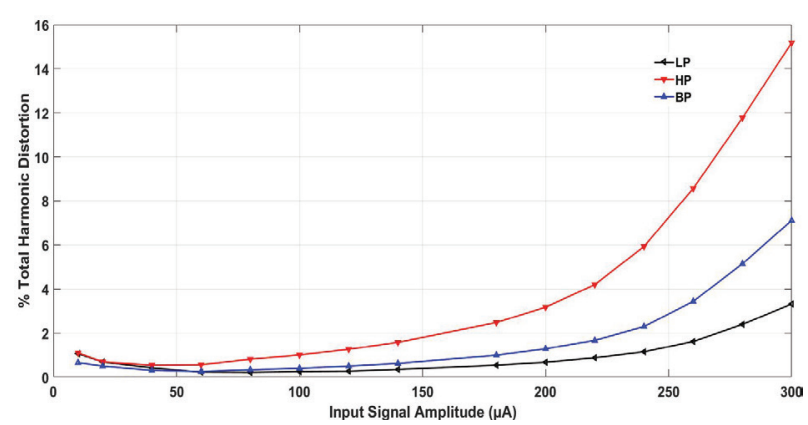

Figure 17: CM SIMO configuration: The THD analysis results of the LP, HP, and BP filter

The TAM filter responses are given in Figures 18 and 19 , which prove that the filter can generate all five responses in this mode. The BR and AP responses can be obtained by summing the $I_{H P} I_{L P}$ and $I_{B P}$ currents.

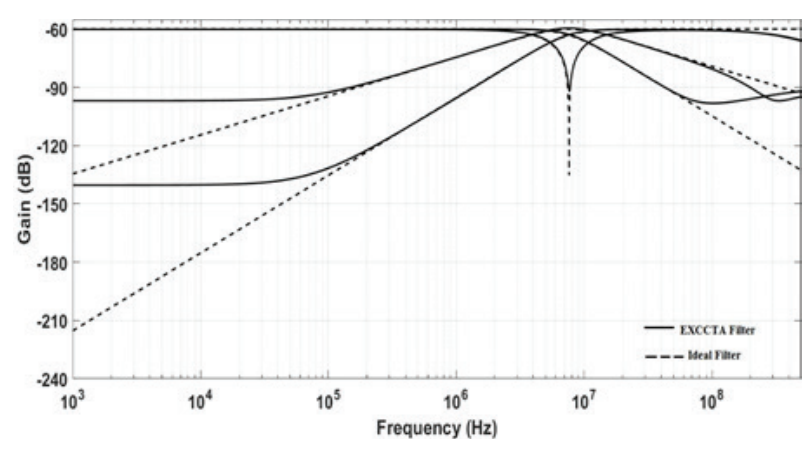

Figure 18: TAM SIMO configuration: Frequency responses of the LP, BP, HP, and BR filter 


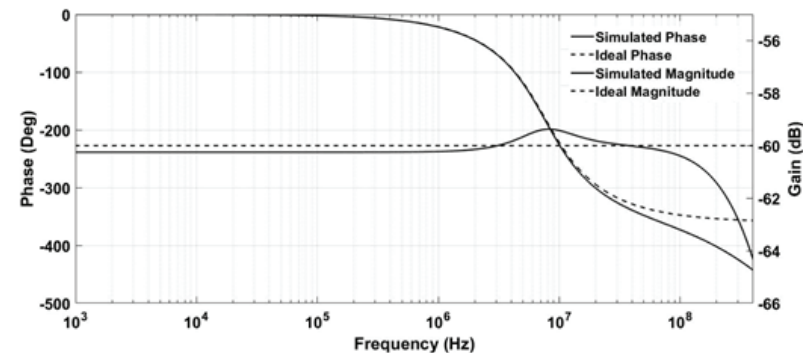

Figure 19: TAM SIMO configuration: Gain and phase responses of the AP filter

The $L P, B P$, and HP responses in TIM configuration are shown in Figure 20. The AP response is given in Figure 21 . To verify the frequency tunability the LP response is plotted for different values of resistance $R_{2}$. Figure 22 shows that the frequency tuning also effects the $Q$ of the filter, however, it can be adjusted independent of frequency by varying $I_{\text {Bias } 1}$ of OTA1.

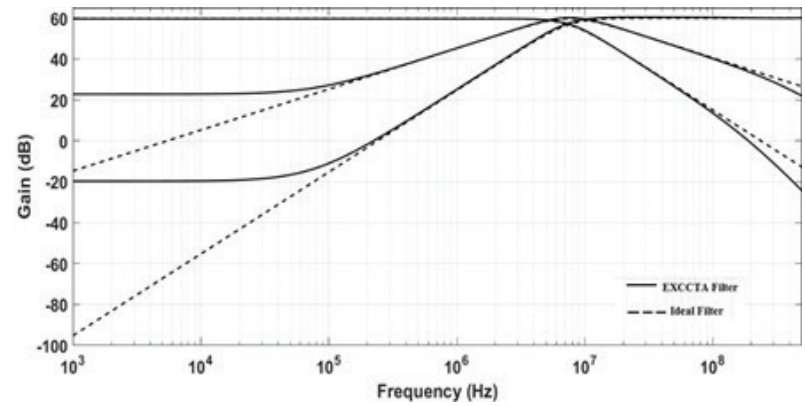

Figure 20: TIM SIMO configuration: Frequency responses of the LP, BP, and HP filter

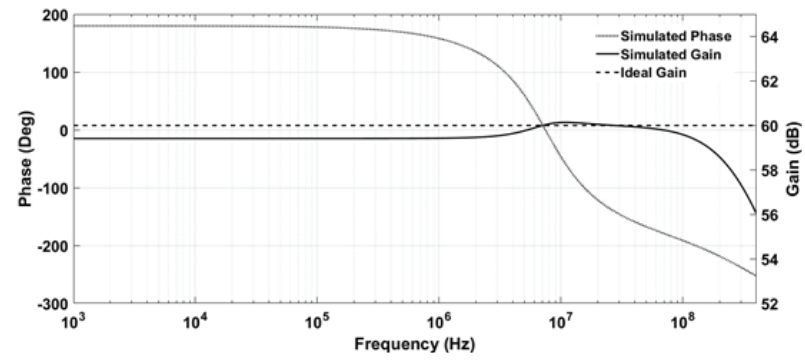

Figure 21: TIM SIMO configuration: Gain and phase responses of the AP filter

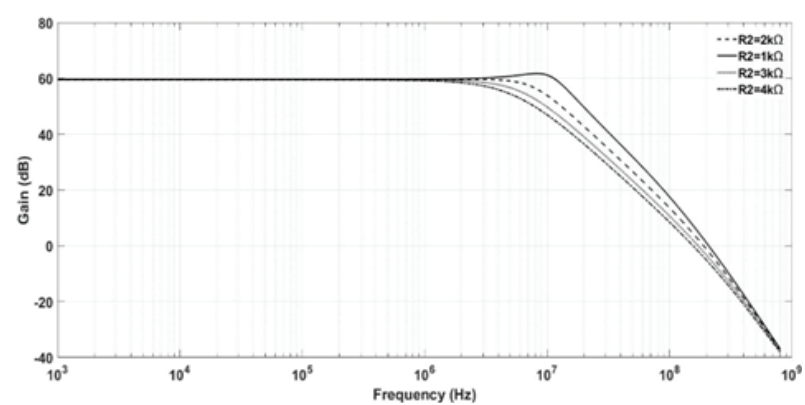

Figure 22: TIM SIMO configuration: Frequency tunability for different values of $R_{2}$ in LP filter

\subsection{MISO VM and TAM configuration operation}

The filter is designed for $f_{0}=7.9577 \mathrm{MHz}$ by setting passive component and OTA bias current values as follows: $R_{1}=1 \mathrm{k} \Omega, R_{2}=1 \mathrm{k} \Omega, R_{3}=969 \Omega, C_{1}=20 \mathrm{pF}, C_{2}=20$ $\mathrm{pF}$, and $\mathrm{g}_{\mathrm{m} 1}=\mathrm{g}_{\mathrm{m} 2}=1.0321 \mathrm{mS}$. It must be noted that in MISO configuration resistor $R_{4}$ is not required and will be removed. The inputs are applied according to conditions outlined in Table 2. The filter provides VM and TAM responses simultaneously from the same input sequence. The VM filter responses are presented Figure 23. The VM AP response is given in Figure 24. The independent tunability of the $Q$ is depicted in Figure 25 for


and signal processing accuracy of the filter, transient analysis is done at $7.9577 \mathrm{MHz}$ with sinusoidal voltage input of $200 \mathrm{mV}(p-p)$ for BP configuration. Figure 26 validates the correct functioning of the filter.



Figure 23: VM MISO configuration: Frequency responses of the LP, BP, HP, and BR filter

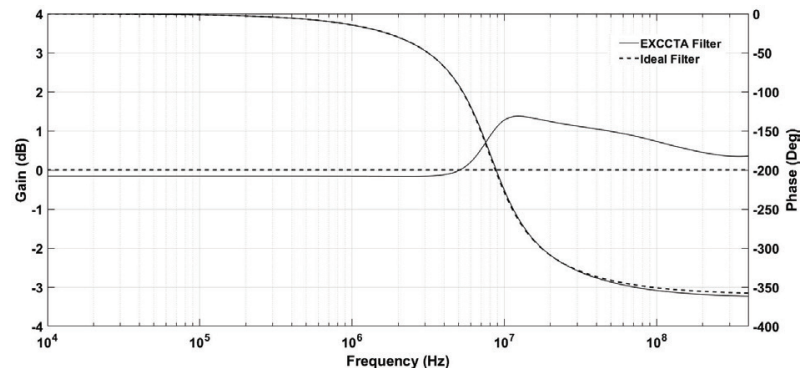

Figure 24: VM MISO configuration: Gain and phase responses of the AP filter

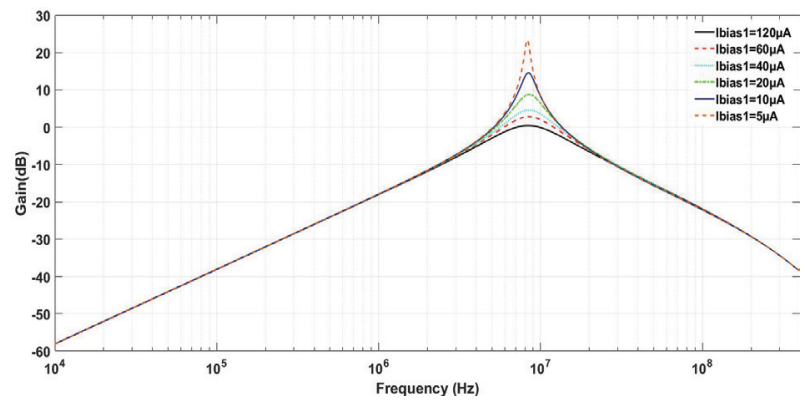

Figure 25: VM MISO configuration: Quality factor tuning for different bias currents in BP filter 




Figure 26: VM MISO configuration: Transient analysis of BP filter

The TAM responses of the MISO filter are presented in Figure 27. The AP response is given in Figure 28. The VM outputs are obtained from low impedance node and TAM outputs are obtained from explicit high impedance node which make this filter cascadable.

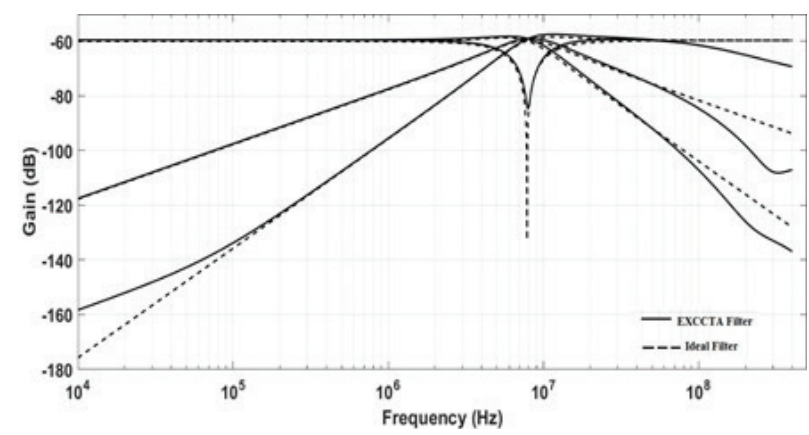

Figure 27: TAM MISO configuration: Frequency responses of the LP, BP, HP, and BR filter

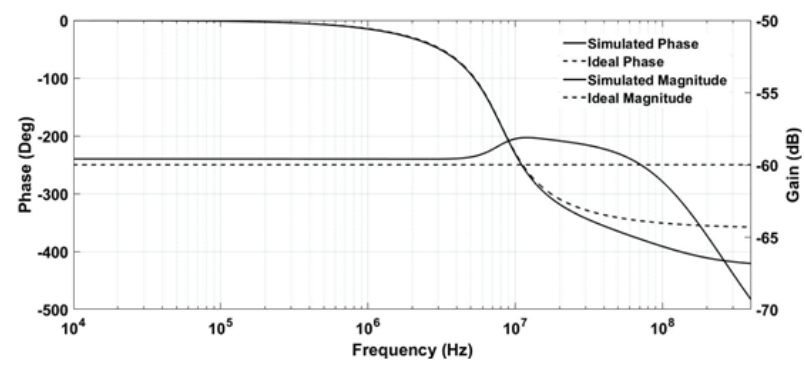

Figure 28: TAM MISO configuration: Gain and phase responses of the AP filter

\subsection{MISO CM and TIM configuration operation}

The CM and TAM filter is designed for $f_{0}=8.16 \mathrm{MHz}$ by setting passive component and OTA transconductance values as follows: $R_{1}=1 \mathrm{k} \Omega, R_{2}=1 \mathrm{k} \Omega, R_{3}=969 \Omega, C_{1}=20$ $p F, C_{2}=20 \mathrm{pF}$, and $g_{\mathrm{m} 1}=g_{\mathrm{m} 2}=1.0321 \mathrm{mS}$. In MISO filter there is again no need for $R_{4}$. The inputs currents are applied according to sequence given in Table 3. The filter provides CM and TIM responses simultaneously from the same input sequence. The CM outputs are available from explicit high impedance node and the TIM outputs are available from low impedance node mak- ing the filter cascadable. The CM responses are given in Figures 29, 30 and the TIM responses are presented in Figures 31, 32.

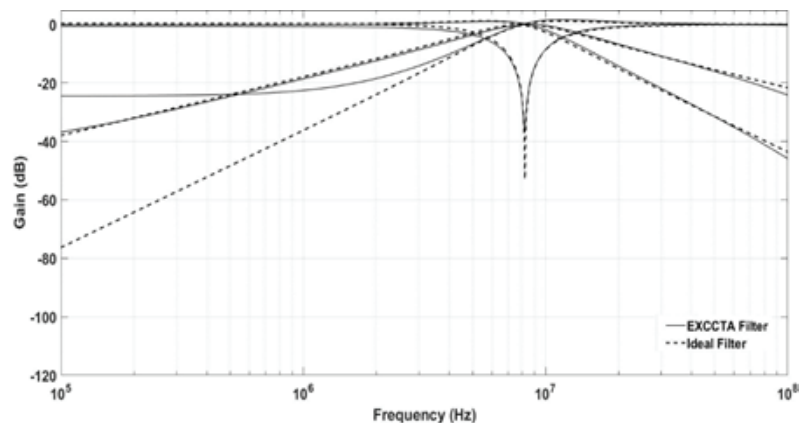

Figure 29: CM MISO configuration: Frequency responses of the LP, BP, HP, and BR filter



Figure 30: CM MISO configuration: Gain and phase responses of the AP filter

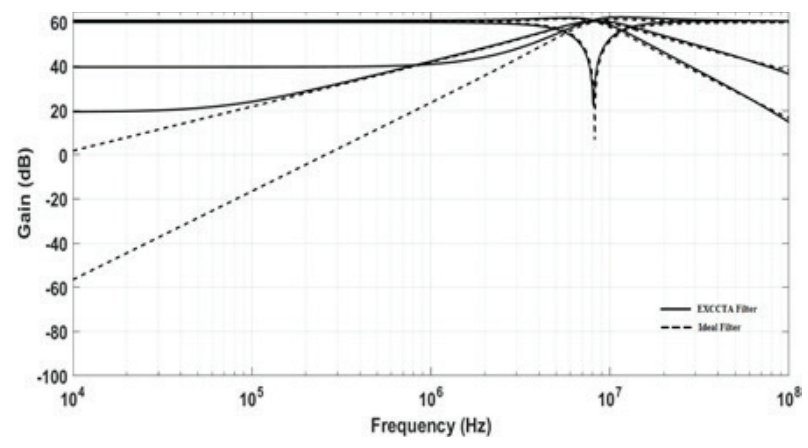

Figure 31: TIM MISO configuration: Frequency responses of the LP, BP, HP, and BR filter

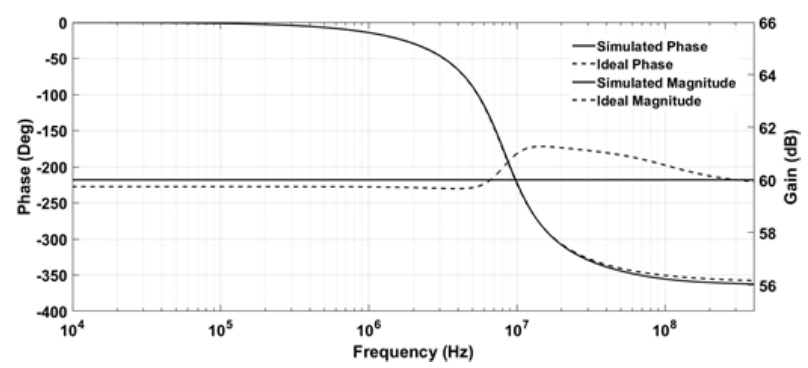

Figure 32: TIM MISO configuration: Gain and phase responses of the AP filter 
The proposed filter is validated in both MISO and SIMO configurations. The filter responses are found close to the theoretical ones. In CM and TAM operation, the filter response degrades beyond $350 \mathrm{MHz}$ as seen from the graphs. This problem can be mitigated by increasing the output impedance of $Z_{\mathrm{p}}$ and $Z_{N}$ terminals by employing cascode transistors in the output stage. Moreover, careful layout can further increase the accuracy of the filter.

\section{Conclusion}

In this study, a new EXCCTA based electronically tunable mixed-mode filter structure is proposed. The filter employs two EXCCTAs, four resistors, two capacitors, and a single switch. This is the first presented filter to date that has inbuilt tunability and can realize all five filter responses in all four modes of operation (VM, CM, TAM, and TIM) in both MISO and SIMO configurations. The detailed theoretical analysis, non-ideal gain analysis, and sensitivity study are given. The layout of the EXCCTA is designed in Cadence software and extensive simulations are carried out to examine and validate the proposed filter in all four modes of operation. The proposed filter has the following advantages: (i) ability to operate in both MISO and SIMO configurations in all four modes, (ii) no requirement of capacitive matching, (iii) low input impedance in SIMO (CM and TIM) configuration, (iv) high output impedance explicit current output for SIMO (CM and TAM), (v) tunability of $Q$ independent of frequency in MISO and SIMO configurations, (vi) use of grounded capacitors in SIMO configuration, (vii) low output impedance for MISO (VM and TIM), (viii) high output impedance explicit current output for MISO (CM and TAM), (ix) no requirement for double/negative input signals (voltage/current) in MISO configuration, and (x) low active and passive sensitivities. The simulation results are consistent with the theoretical predictions.

\section{Acknowledgement}

This work is funded by Minister of Education Malaysia under grant FRGS/1/2018/TK04/UKM/02/1 and AKU254:HICoE (Fasa II) 'MEMS for Biomedical Devices (artificial kidney).

\section{References}

1. P.V.A. Mohan, Current-mode VLSI analog filters design and applications, Springer Science \& Business Media, 2012.
2. G. Ferri, N.C. Guerrini, Low-voltage low-power CMOS current conveyors, Springer Science \& Business Media, 2003.

3. R. Raut, M.N.S. Swamy, Modern analog filter analysis and design: a practical approach, John Wiley \& Sons, 2010.

4. H.P. Chen, Voltage-mode multifunction biquadratic filter with one input and six outputs using two ICClls, Sci. World J. (2014) 432570:1-7. https://doi.org/10.1155/2014/432570.

5. M. Faseehuddin, J. Sampe, S. Shireen, S. Hamid, Minimum Passive Components Based Lossy and Lossless Inductor Simulators Employing a New Active Block, AEU - Int. J. Electron. Commun. 82 (2017) 226-240. https://doi.org/10.1016/j.aeue.2017.08.046.

6. R. Senani, D.R. Bhaskar, A.K. Singh, Current conveyors: Variants, applications and hardware implementations, Springer Science \& Business Media,2015.

https://doi.org/10.1007/978-3-319-08684-2.

7. M. Taher, M.T. Abuelma'atti, A novel mixed-mode current-controlled current-conveyor-based filter, Active and passive electronic components 26 (2003) 185-191.

8. H.P. Chen, Y.Z. Liao, W.T. Lee, Tunable mixed-mode OTA-C universal filter, Analog Integrated Circuits and Signal Processing (2009) 135-141.

https://doi.org/10.1007/s10470-008-9228-z.

9. M. Taher, M.T. Abuelma'atti, A. Bentrcia, A novel mixed-mode CCII-based filter, Active and Passive Electronic Components 27 (2004) 197-206.

10. A. Yesil, F. Kacar, Electronically Tunable Resistorless Mixed Mode Biquad Filters, Radioengineering (2013) 1016-1025.

11. A.M. Soliman, Mixed-mode biquad circuits, Microelectronics Journal 27 (1996) 591-594.

12. D. Singh, N. Afzal, Fully Digitally Programmable Generalized Mixed Mode Universal Filter Configuration, Circuits, Syst. Signal Process. 35 (5) (2016) 1457-1480.

https://doi.org/10.1007/s00034-015-0125-2.

13. S. Maheshwari, Realization of Simple Electronic Functions Using EXCCII, J. Circuits, Syst. Comput. 26 (2017) 1750171.

https://doi.org/10.1142/S0218126617501717.

14. D. Biolek, R. Senani, V. Biolkova, Z. Kolka, Active elements for analog signal processing: Classification, review, and new proposals, Radioengineering. 17 (2008) 15-32.

15. M. Faseehuddin, J. Sampe, S. Shireen, Lossy and Lossless Inductance Simulators and Universal Filters Employing a New Versatile Active Block, Informacije MIDEM, 48 (2018) 97-113.

16. V.K. Singh, A.K. Singh, D.R. Bhaskar, R. Senani, Novel mixed-mode universal biquad configuration, 
IEICE Electronics Express 2(22) (2005) 548-553. https://doi.org/10.1587/elex.2.548.

17. N.A. Shah, M.A. Malik, Multifunction Mixed-Mode Filter using FTFNs, Analog Integr. Circuits Signal Process. 3 (2006) 339-343.

18. C.N. Lee, C.M. Chang, Single FDCCII-based mixedmode biquad filter with eight outputs, AEU - Int. J. Electron. Commun. 63 (2009) 736-742. https://doi.org/10.1016/j.aeue.2008.06.015.

19. L. Zhijun, Mixed-mode universal filter using MCCCII, AEU - Int. J. Electron. Commun. 63 (2009) 1072-1075.

https://doi.org/10.1016/j.aeue.2008.09.003.

20. S. Minaei, M.A. Ibrahim, A mixed-mode KHNbiquad using DVCC and grounded passive elements suitable for direct cascading, International Journal of Circuit Theory and Applications 37(7) (2009) 793-810. https://doi.org/10.1002/cta.

21. S. Maheshwari, S.V. Singh, D.S. Chauhan, Electronically tunable low-voltage mixed-mode universal biquad filter, IET Circuits, Devices \& Systems 5(3) (2011) 149-158. https://doi.org/10.1049/iet-cds.2010.0061.

22. S. V Singh, S. Maheshwari, D.S. Chauhan, Electronically Tunable Current / Voltage- mode Universal Biquad Filter using CCCCTA, International J. of Recent Trends in Engineering and Technology 3(3) (2010) 71-76.

23. W. Liao, J. Gu, SIMO type universal mixed-mode biquadratic filter, Indian Journal of Engineering \& Materials Science18 (2011) 443-448.

24. H. Chen, W. Yang, Electronically Tunable Current Controlled Current Conveyor Transconductance Amplifier-Based Mixed-Mode Biquadratic Filter with Resistorless and Grounded Capacitors, Applied Sciences 7(3) (2017). https://doi.org/10.3390/app7030244.

25. V. Chamnanphai, W. Sa-ngiamvibool, Electronically Tunable SIMO Mixed-mode Universal Filter using VDTAs, Przegląd Elektrotechniczny 93(3) (2017) 207-211. https://doi.org/10.15199/48.2017.03.48.

26. H. Mahmoodian, A Low-Power Mixed-Mode SIMO Universal $\mathrm{G}_{\mathrm{m}}-\mathrm{C}$ Filter, Journal of Circuits, Systems and Computers 26(10) (2017). https://doi.org/10.1142/S021812661750164X.

27. J. Horng, C. Wu, N. Herencsar, Current-mode and transimpedance-mode universal biquadratic filter using two current conveyors, Indian Journal of Engineering \& Materials Science 24 (2017) 461468.

28. M.T. Abuelma'atti, A. Bentrcia, M. Al-shahrani, A novel mixed-mode current-conveyor-based filter, International Journal of Electronics 91(3) (2004) 191-197. https://doi.org/10.1080/0020721041000167703.

29. N. Pandey, S.K. Paul, A. Bhattacharyya, S.B. Jain, A new mixed mode biquad using reduced number of active and passive elements, IEICE Electronics Express 3(6) (2006) 115-121.

https://doi.org/10.1587/elex.3.115.

30. C. Lee, Multiple-Mode OTA-C Universal Biquad Filters, Circuits, Systems and Signal Processing 29(2) (2010) 263-274. https://doi.org/10.1007/s00034-009-9145-0.

31. N. Pandey, S.K. Paul, A. Bhattacharyya, S.B. Jain, Realization of Generalized Mixed Mode Universal Filter Using CCCIls, Journal of Active \& Passive Electronic Devices 5 (2010) 279-293.

32. N. Pandey, S.K. Paul, Mixed mode universal filter, Journal of Circuits, Systems and Computers 22(01) (2013) 1-10.

https://doi.org/10.1142/S0218126612500648.

33. C.N. Lee, Independently tunable mixed-mode universal biquad filter with versatile input/output functions, AEU - Int. J. Electron. Commun. 70 (2016) 1006-1019. https://doi.org/10.1016/j.aeue.2016.04.006.

34. T. Tsukutani, N. Yabuki, A DVCC-Based MixedMode Biquadratic Circuit, Journal of Electrical Engineering 6 (2018) 52-56. https://doi.org/10.17265/2328-2223/2018.01.008.

35. A. Fabre, O. Saaid, H. Barthelemy, On the frequency limitations of the circuits based on second generation current conveyors, Analog Integr. Circuits Signal Process. 7(2) (1995) 113-129.

36. B. Chaturvedi, J. Mohan A. Kumar, A new versatile universal biquad configuration for emerging signal processing applications. Journal of Circuits, Systems and Computers, 27(12), 1850196. https://doi.org/10.1142/S0218126618501967

37. C.N Lee, Mixed-mode universal biquadratic filter with no need of matching conditions. Journal of Circuits, Systems and Computers, 25(09), 1650106.

https://doi.org/10.1142/S0218126616501061.



Copyright $\odot 2020$ by the Authors. This is an open access article distributed under the Creative Commons Attribution (CC BY) License (https://creativecommons.org/licenses/by/4.0/), which permits unrestricted use, distribution, and reproduction in any medium, provided the original work is properly cited.

Arrived: 15. 05. 2020

Accepted: 14. 10. 2020 